\title{
Inimene eesti võrdlustes
}

$\underline{\text { Katre Öim }}$

Võrdluste struktuuris tavatsetakse eristada järgmisi osi: võrdlusobjekt (ingl k tenor), võrdlusalus (ingl k ground) ja võrdlusvahend (ingl k vehicle). Eesti väljendis suu kuiv nagu saapatald on suu võrdlusobjektiks, kuiv võrdlusaluseks ja saapatald võrdlusvahendiks.

Järgnevas kirjutises jälgin võrdlusvahendi mõistelist jagunemist ja püüan vastata mõnedele küsimustele:

1. kui sageli võrreldakse meie traditsioonilistes võrdlustes kedagi/midagi mõne olendiga ja kui laialt on levinud kõrvutamine mõne elutu objektiga (opereerin siin distinktiivtunnustega elus ja elutu);

2. milline on inimese osakaal elusolendite hulgas;

3. kui sageli on võrdlusvahendiks inimene kui selline või kui sageli võrreldakse spetsifitseeritud inimesega.

Lisaks pööran tähelepanu ka sellele, kas üks või teine inimesekujuline olend eksisteerib reaalselt või on tegemist väljamõeldisega, samuti sellele keda/mida inimesega võrreldakse.

\section{Sissejuhatus}

Järgnevas on huviobjektiks võrdlusvahendina esinev inimene (semantiliste tunnustega elus ja inimlik).

Olgu kohe mainitud, et võrdluste mistahes analüüsi puhul tuleb arvestada nende elliptilise struktuuriga. Võrdlusvahend on ainus element, mis kuulub eranditult kõigi võrdluste koosseisu (Õim 1997: 24) -- seetõttu vaatlen just selle komponendi seotust inimesega. Kindlasti oleks huvitav jälgida ka seda, kui sageli on inimene võrdlusobjektiks, samuti seda, millisest inimese omadusest räägitakse. Asja muudab keeruliseks kontekstide vähesus allikmaterjalis.

Tõuke eesti võrdluste selle tahu uurimiseks andis kõnekäänukartoteegis leiduv väike rühm vaimukaid ja emotsionaalseid võrdlusetüüpe, milles kõigis on võrdlusvahendiks tõenäoliselt inimest tähistav tegijanimi:

$\begin{array}{lll}\text { süda vesine kui kalapüüdjal } & \text { loru nagu härjaajaja } & \text { nagu varesevihtleja } \\ \text { mokad punnis kui } & \text { käib nagu hernekülija } & \text { nagu uppuja võtab õlekõrrest kinni } \\ \text { pasunapuhujal } & \text { nina jookseb kui } & \text { kui higi tammitegija } \\ \text { näost valge kui vallakirjutaja } & \text { võidujooksja } & \text { suu muhkus nagu munaotsijal } \\ \text { riides nagu karutantsitaja } & \text { pahane nagu emamatja } & \text { suu lahti kui vihmaootajal teist } \\ \text { jämedad jalad nagu } & \text { pakitseb kui moka uutja } & \text { kolmat päeva } \\ \text { karutantsitajal } & \text { pisike kui kilgikohija } & \text { nagu niidse kiskuja } \\ \text { läheb kui maamõotja } & \text { pisike kui kirvekeetja } & \text { kui täi nilgjö } \\ \text { märg nagu seeneotsija } & \text { punane nagu } & \text { nagu sureja otsib aset } \\ \text { must nagu korstnapühkija } & \text { pullilõikaja } & \text { nagu surejale rohi } \\ \text { nagu maoajaja } & \text { silmad kui kerisekasijal } & \text { väriseb nagu hallisõitja } \\ \text { jooksevad ümber nagu } & \text { taob kui härjatapja } & \text { kõnnib kui kõhupõdeja } \\ \text { soldanivõtjad } & \text { tolmune nagu } & \text { muren kui kuulja } \\ \text { kang hõlma all nagu } & \text { kütisekütja } & \text { heidutse nagu hulkujat kunagi }\end{array}$




\section{kabelilõhkujal}

tõttab kui sitalt tulija

käed värisevad kui kassitapjal õhetab nagu saunast

kõht täis kui rehepeksjal

rinnad vallale nagu

kassiimetajal

silmad vesised kui

soolavakategijal

sõrmed otsas kui tõrre

vitsutajal

süda täis kui seatapjal

söövad nagu töötegijad tulija

nagu elavaneelataja

nagu kiurumunetaja

nagu käisest imeja

nagu loogaheitja

justkui roomasikutaja noomib nagu kirikuõpetaja

väsinud ilme nagu kirikuõpetajal

tõsine kui juudi võlamaksja

\section{Kas võrdlusvahend on olend või mitteolend}

Vaatlesin võrdlusi kõigepealt sellelt seisukohalt, kui sageli on võrdlusvahendiks mõni olend. Kõike ülejäänut (muuhulgas nt kehaosi, nähtusi, tundeid, üritusi jne) pidasin siin "asjade" hulka kuuluvaks.

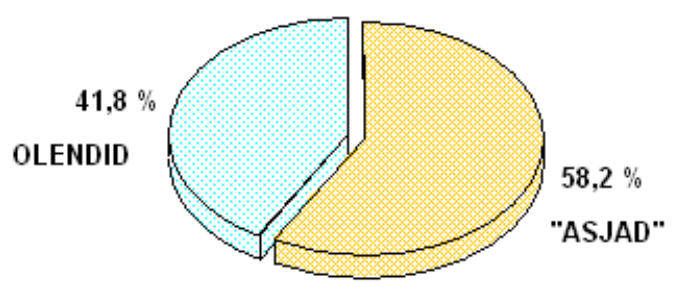

\section{Joonis 1. Elusolendid ja "asjad" võrdlusvahendina}

Näeme, et tegemist on suhteliselt väikese eelistusega "asjade", st mitteolendlike denotaatide kasuks. Kohe tuleb rõhutada seda, et need kaks kogumit ei ole oma sisemiselt struktuurilt sugugi ühesugused. Ühesse kuuluvad ainult metsloomad (k.a linnud, putukad, kalad), koduloomad ja inimesed, samal ajal kui neile vastanduvad (nagu eespool öeldud) objektid vägagi erinevatest valdkondadest. Seetõttu vaatame siinkohal lähemalt ainult seda, kes elusolendite hulgas domineerib ja milline on inimese osakaal selles valimis. 
3. Kellega eesti võrdlustes võrreldakse

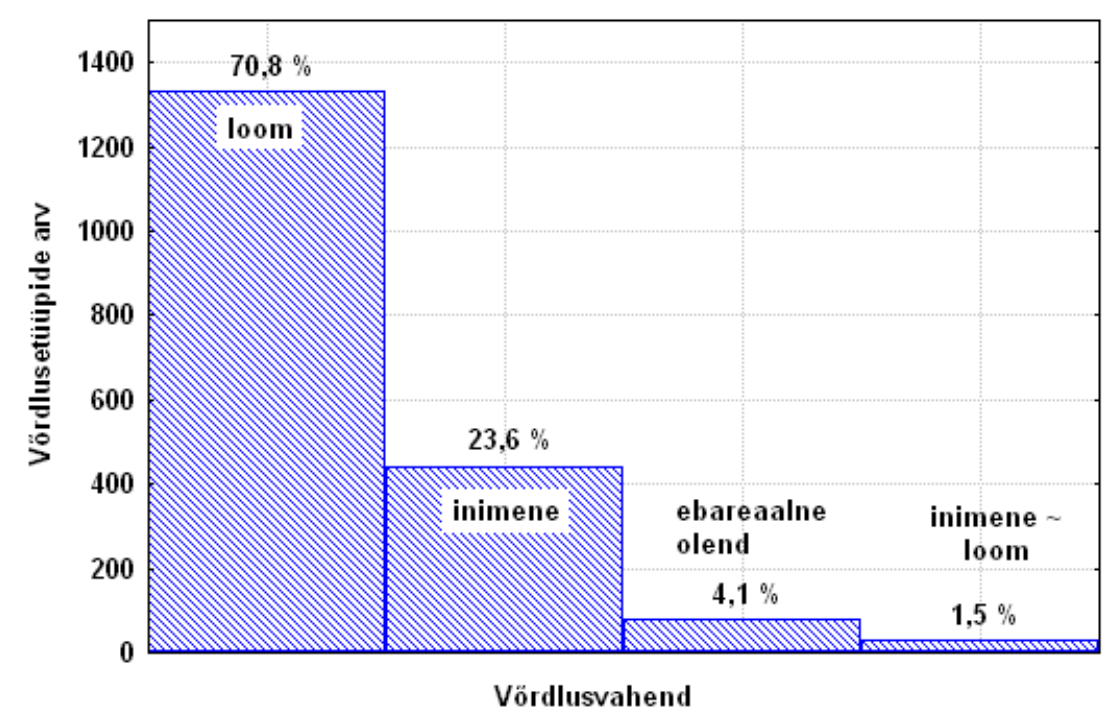

Joonis 2. Võrdlusvahendiks valitud elusolendite sagedusjaotus

- Võrdlusvahend on ülekaalukalt valitud loomastiku hulgast (1330 võrdlusetüüpi). Võrdlemist metsloomadega ülaltoodud tähenduses (nt kardab tööd kui hunt maru) ja koduloomadega (nt kaval kui karjakoer rebase kõrval), esineb enam-vähem võrdse sagedusega. Üksikutel juhtudel (kokku 26 tüüpi) on leksikaalsete vahenditega näidatud, st rõhutatud, et loom (või lind vm) on surnud (s.t tunnus elus enam ei kehti), nt hambad irevil kui koolnud rebasel, silmad kinni kui surnud seal. Surnud loomi ei ole paigutatud "asjade" rühma, sest silmas on peetud eelkõige nende mõistelist kuuluvust. On tähelepanuväärne, et nii suure hulga väljendite puhul on vaid paaril korral tavapärase zoonüümi asemel kasut atud tegijanime: silmad nagu õlesööjal ('härg'), jalad kui metetoojal ('mesilane').

- 77 tüübis on võrdlusvahendiks enamasti mütoloogiline olend, piiblitegelane vm, nt nagu külmking, kaval nagu vanapagana kutsikas, nagu jeesuke ristis. 22 tüübis sellest hulgast võrreldakse inimkujulise figuuriga, nt istub nagu Petlema koldevaht, karvane kui Jeesav, siia kuuluvad ka võrdlused Kalevipojaga, nt tugev kui Kalevipoeg, kasinasti kui Kalevipoeg.

- 28 võrdlusetüübi puhul pole üheselt selge, kas võrdlusvahend tähistab inimest või looma -- siin ei nimetata ühtki elusolendit otsesõnu, vaid mingi omaduse kaudu, mida võib omistada nii inimesele kui loomale (samas pole kindel, et sellised võrdlusvahendid tähistavad ainult elusolendit). Nt kui raanits, nagu neelund, nagu vilask. Võiks arvata, et sellistes väljendites on sidesõnal tõenäoliselt vähem kõrvutav ja rohkem n-ö leevendav ülesanne -- selle asemel, et öelda nt igavene vilask, mis kõlab üsna halvustavalt, kasutatakse sidesõnaga konstruktsiooni.

- 443 tüübis märgib võrdlusvahend inimest. Vaid ühel juhul nimetatakse siin inimest kui liiki: rahvast rohkem kui inimesi (kuid siingi on tegu pigem sõnamängu kui võrdlemisega); paaril korral on võrdlusvahendiks enesekohane asesõna: tunneb teda kui iseennast, süda suurem kui ise. Valdavalt iseloomustatakse võrdlusvahendiks olevat inimest täpsemalt. Pisut üle 20 võrdlusetüübi puhul on võrdlusvahendiks olev inimene tähistatud pärisnimega, nt käib korstnast välja nagu Naba Tõnn (samas ei anna aga pärisnimi teate vastuvõtjale tundmatu kõnealuse isiku kohta iseenesest mitte mingisu- 
gust infot -- siit ka selliste tüüpide väike hulk, st levik. (Ka Iris Järviö-Nieminen (Järviö-Nieminen 1959) rõhutab vellerisme uurides, et enamik pärisnimelistest vellerismidest on lühiealised, lähtuvad konkreetseist juhtumitest, ei levi enamasti kaugele, nende edu põhineb prototüüpide tuntusel jne.) Ülejäänud, st enamikel juhtudel rõhutatakse inimese tegevusala, sotsiaalset rolli vms, st tuuakse esile mõni rohkem või vähem oluline aspekt inimtegevusest või -ühiskonnast ja võrreldakse selle kaudu. Võrdlusvahendite temaatilist katkendlikkust illustreerib järgnev jaotus.

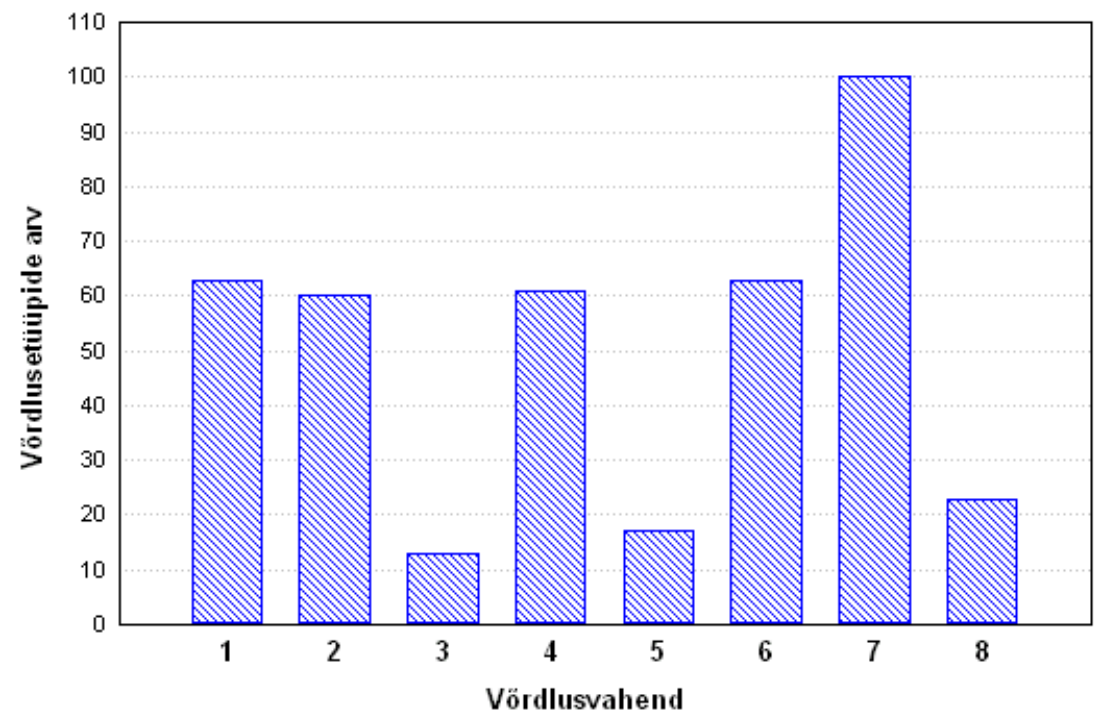

Joonis 3. Millise inimesega võrreldakse

1 -- elukutse $\sim$ ameti $\sim$ elatusala esindaja; 2 -- tegevuse sooritaja; 3 -teatud omadusega inimene; 4 -- sugulane $\sim$ mees/naine; 5 -- üritusest osavõtja; 6 -- inimene ühiskondliku seisundi või suhete järgi; 7 -inimene etnilise päritolu järgi; 8 -- inimene nimeliselt

- Nii nagu teisteski lühivormides, samuti naljandites ja anekdootides (vt ka Taylor 1931), peetakse ka võrdlustes oluliseks inimese etnilist kuuluvust. Etniline spetsifikatsioon nähtub u 100 võrdlusetüübis, kusjuures valdava osa moodustavad siin kõrvutamised teiste rahvaste, st mitte-eestlastega. Ootuspäraselt kuuluvad esikolmikusse rahvad, kes elavad eestlaste hulgas või kõrval: mustlased (27 tüüpi), juudid (23 tüüpi) ja venelased (14 tüüpi), nt nagu mustlased jagavad Sirtsu soos kopsu, loodab nagu juut tühja tõrre sisse, kui üle-järve venelane. 15 tüübis on võrdlusvahendiks Eesti eri paikkondade elanikud (nt nagu kihnlane ei saa suitsu pärast naist jää vahelt välja aidata), kusjuures mainitakse vaid saarte elanikke ja lõunaeestlasi, täpsemalt mulke ja setusid (seega perifeeriate elanikke).

Võrdselt aktuaalsed on järgmised spetsifikatsioonid -- igaüks esindatud u 60 võrdlusetüübiga.

- Elukutse, amet, elatusala, kusjuures kokku on kasutatud 36 erinevat nimetust, nt laseb nagu lukussepp, isandakene kui kõrtsimees, kõva häälega kui küla karjamees.

- Tegevus (võrdlusvahendiks on tegevuse sooritaja), nt tolmune nagu kütisekütja, valge nagu veskiline. Kõnealused tegevused on väga erineva "kvaliteediga": 1) nt kõht täis kui rehepeksjal, käib nagu hernekülija -- võrdlusvahend viitab normaalsele ajutisele tegevusele; 2) nt kang hõlma all nagu kabelilõhkujal, rinnad vallale nagu kassiimetajal, pisike kui kilgikohija, pisike kui kirvekeetja, -- võrdlusvahend viitab absurdsele tegevusele, mida võib füüsiliselt küll ette kujutada, kuid tegelikus elus nii ei toimita; 
3) nt pikk kui pilvelõhkuja, kui higi tammitegija, nagu kiurumunetaja -- võrdlusvahend viitab absurdele tegevusele, mida on raske isegi ette kujutada.

Samas on absurdlike võrdlusvahenditega võrdlused väga assotsiatiivsed; absurdielementide kasutamine suurendab naljaelamust, mida üldiselt peetakse fraseologismidele omaseks (vt Krikmann 1997: 42, 43).

- Sugulussuhted, nt ópeta nagu oma last, ja sugupooled, nt nagu vana naine, kellel julgus puudub.

- Omandi- ja klassisuhted, nt laiad püksid kui rikka pere väimehel, justkui sandid Sindi tee otsas, sotsiaalsed institutsioonid, nt noomib nagu kirikuõpetaja. Pole võimatu, et inimene, kellega võrreldakse, on surnud: oota kui surnud sant matjat.

Järgmised kaks teemat leiavad võrdlusvahendi puhul kasutust suhteliselt harva -- mõlemad on esindatud u 20 võrdlusetüübiga.

- Haigused (ka surm), nt mäletseb nagu veetõbine, nagu pime viskab kiviga, külmad käed kui surnul ja halvad harjumused, st suitsetamine ja joomine, nt sülgab nagu piibumees, krabab käega seina kui joodik kuradit.

- Üritused, nt hõiskab kui pulmaline, nagu pulma peremees paljajalu, ehib ennast nagu kirikuline.

- 13 tüübi puhul on võrdlusvahendis tähistatud inimest sõnaga, mille põhitähenduseks on mingi omadus. Sarnaselt väljenditega, kus võrdlusvahendiks on tegevuse sooritaja, kasutatakse siin võrdlusvahendiks olevat sõna ka iseseisvalt (s.t väljaspool võrdluskonstruktsiooni), kuid tähendus sellest ei muutu. Nt must nagu murjan, must nagu mursa.

Siin ja sissejuhatuses toodud näidete puhul ei ole raske märgata, et inimreferenti tähistava võrdlusvahendi puhul on produktiivseks sõnamoodustusviisiks ja-liite kasutamine. $j a$-tuletisi e tegijanimesid moodustatakse eesti keeles rohkesti vahetult tekstis, nt järjekorrataja (EKG 1993: 480, 482). Suur osa eespool nimetatud rühma "tegevuse sooritaja" kuuluvatest väljenditest sisaldab minu arvates just selliseid, justkui ainult fraseoloogiliseks kasutamiseks moodustatud tegijanimesid, mis väljaspool fraseologisme levinud ei ole, nt justkui roomasikutaja.

Võrdlusvahendi inimkeskset temaatilist rõhuasetust kokku võttes, võib öelda, et eesti keeles võrreldakse liigi- või pärisnimelise inimesega (s.t ei tooda esile ühtki külge inimese tegevustest/omadustest, päritolust ja muust, vaid nimetatakse ainult teda ennast) väga harva. Kui võrdlusvahendiks valitud inimest nimetatakse pärisnimega, siis on loogiline selle piiratud ulatus -- isik on tuntud teatud alal, millest kaugenedes ei teata tema tegudest/omadustest midagi; ütlemisest ei saada aru, seda peetakse igavaks (vastupidiselt taotlusele) ja väljend kaob käibelt. Hoopis sagedamini tehakse inimesega võrdlemisel tema tegevustest, omadustest valik ja rõhutatakse seda -- nii antakse võimalikult täpne viide sellele, mida tahetakse öelda. Inspireerijana eelistatakse inimese etnilist päritolu.

\section{Keda (või mida?) ja mille poolest inimesega võrreldakse}

Kui uurida eespool kirjeldatud võrdluste võrdlusobjekti, siis ilmneb üllatav olukord. Nimelt on võrdlusobjekt käsitletava allikmaterjali hulgas manifesteeritud täiesti tühisel määral -- selliseid tüüpe on 13, kusjuures üheksal juhul võrreldakse omavahel kahte inimest, neljal juhul midagi somaatilist (mis eeldatavasti kuulub inimesele) inimese või inimeste kogumiga. $\mathrm{Nt}$ tüdrukud nagu märsikud; mees nagu mürakas; lapsed kui kaagid; mees kui hanekarjus; lapsi kui mudilasi; mees kui papp; sinuga kõnele kui ubamulgiga; käib kosilasi kui veskilisi; paks perse temal taga nagu mõnel perenaisel; kõht nagu vend kõrval; perse nagu teine pere; nina 
jookseb kui võidujooksja. Inimvahendiga võrdluste üleskirjutused kartoteegis sisaldavad harva konteksti -- kõnes koosneb öeldav lause ainult väljendist, midagi siia juurde ei lisata, sest asi peaks niigi selge olema (sest mõtteliselt on lüngad ju täidetud). Kui miski situatsiooni täpsustab, siis on selleks kas isikuline asesõna või abiverb olema ainsuse II või III pöördes. Need üksikud faktid viitavad sellele, et inimesega võrreldakse inimest.

Vaatame lähemalt ka võrdlusalust. Tüübid, kus võrdlusalus kuulub traditsiooni, moodustavad u 65 protsenti, millest omakorda 40 protsendil juhtudest võib kindlalt öelda, et võrdlusaluseks olev omadus, tegevus vm on mõeldav ainult inimese puhul, nt ehib ennast nagu kirikuline. Kui sellele liita ka äsjaloetletud 13 tüüpi, mis sisaldavad inimlikku võrdlusobjekti, siis selgub, et kui võrdlusvahend märgib inimest, siis on vaid 28 protsendil juhtudest päris kindel, et kõrvutatakse kahte inimest. Ka ülejäänud inimkeskse võrdlusvahendiga väljendite puhul on meie endi intuitsioonist, assotsiatsioonidest jne loogiline kujutleda võrdlusobjekti inimesekujulisena. Samas sisaldavad mõned neist võrdlusalust, mille kaudu võib kirjeldada mitte ainult inimest, või puudub võrdlusalus üldse, nt vagusad kui Saaremaa pulmalised, nagu varas. Seega on olemas väike võimalus (väikseks jääks see tõenäoliselt ka edasisel uurimisel), et inimesega ei võrrelda mitte ainult (teist) inimest. Seda kinnitavad ka paar ülaltoodud somaatilist võrdlusobjekti sisaldavat väljendit, mis on üsna erandlikud.

Seega ilmneb, et eesti võrdlusetüüpide hulgas on vaid 2,5 protsenti selliseid, mille puhul ei ole kahtlust, et omavahel võrreldakse kahte inimest. Kui neile lisada väljendid, milles tõenäoliselt võrreldakse inimesi, saame esinemissageduseks u 8 protsenti.

\section{Kokkuvõte}

Jälgides eesti võrdluste inimkesksust, arvestasin nende suuresti väljajättelist struktuuri ja lähtusin sellest, et võrdluse semantikat saab jälgida eelkõige võrdlusvahendi kaudu (see on ainus element, mis kuulub eranditult kõigi võrdluste koosseisu). Käsitlesin võrdlusvahendi inimkesksust ja koondasin tähelepanu inimesele kui olendile.

Selgus, et meie võrdlusetüüpides võrreldakse rohkem kui 40 protsendi tüüpide puhul mingi elusolendiga, kuid vaid u 30 protsenti sellest hulgast on sellised, kus võrdlusvahendiks on inimene. Võrdlustekartoteegis moodustavad inimvahendiga võrdlusetüübid ligikaudu 8 protsenti.

Inimene kui selline (võrdlusvahendiks pärisnimi enesekohane asesõna) on võrdlusvahendiks väga harva. Valdavalt rõhutatakse hoopis inimese tegevusi, omadusi vm, mõnevõrra eelistatavalt aga etnilist päritolu.

Kõigest 2,5 protsendi eesti võrdlusetüüpide puhul on päris kindel, et omavahel kõrvutatakse kahte inimest.

Võib öelda, et eesti võrdlusetüüpides on võrdlemine inimesega vähelevinud.

\section{Kirjandus}

EKG 1993 = Erelt, M. jt. Eesti keele grammatika. I. Tallinn, lk 480, 482.

Järviö-Nieminen, I. 1959. Suomalaiset sanomukset. Helsinki.

Krikmann, A. 1997. Sissevaateid folkloori lühivormidesse I. Tartu, lk 42, 43; 263.

Taylor, A. 1931. The Proverb. Cambridge, Mass.

Õim, K. 1997. Eesti võrdluste struktuur. Magistritöö Tartu Ülikooli eesti keele õppetoolis, Tartu, lk 24. 